\title{
Effects of nitric oxide synthase deficiency on a disintegrin and metalloproteinase domain-containing protein 12 expression in mouse brain samples
}

UWE LENDECKEL $^{1}$, CARMEN WOLKE ${ }^{1}$, HANS-GERT BERNSTEIN $^{2}$ and GERBURG KEILHOFF $^{3}$

\author{
${ }^{1}$ Institute of Medical Biochemistry and Molecular Biology, University Medicine Greifswald, \\ Ernst-Moritz-Arndt University, Greifswald D-17475; ${ }^{2}$ Clinic of Psychiatry, Psychotherapy and Psychosomatic Medicine; \\ ${ }^{3}$ Institute of Biochemistry and Cell Biology, Otto-von-Guericke University, Magdeburg D-39120, Germany
}

Received September 3, 2014; Accepted March 3, 2015

DOI: $10.3892 / \mathrm{mmr} .2015 .3643$

\begin{abstract}
A disintegrin and metalloproteinase domain-containing protein 12 (ADAM12) belongs to the ADAM family of transmembrane proteins. Via proteolysis, cell adhesion, cell-cell fusion, cell-matrix interaction and membrane protein shedding, ADAM proteins are involved in normal brain development, and also in cancer genesis and progression, and in inflammation. Therefore, neurobiological research focusing on this protein is increasing. Nitric oxide (NO), which is endogenously produced by NO synthases (NOS), is associated with glial tumors. However, knock-out of NOS produces only limited antitumor effects. The present study analyzed the expression of ADAM12 in the cortex and hippocampus of C57/BL6 wild-type mice, and endothelial NOS-, neuronal NOS- (nNOS) or inducible NOS (iNOS)-deficient $\left({ }^{-/}\right)$mice, at different stages of development. Expression of ADAM12 was quantified using immunoblot analysis of cortical and hippocampal tissue samples from fetal, neonatal ( 5 days postnatal), adult ( 12 weeks old) or $>1$ year old mice. Using reverse transcription-quantitative polymerase chain reaction, ADAM12 expression was analyzed in cultured N9, OLN93, C6 and PC12 cells, representing the four main cell types in the brain, following NOS inhibition. ADAM12 expression was low in all mouse genotypes and regions of the brain, and in fetal and neonatal mice, an increase in expression was observed with increasing age. The highest levels of expression were observed in the cortex of adult mice, $\mathrm{iNOS}^{-1-}$ mice of $>1$ year and wild-type mice, and in the hippocampus of adult and $\mathrm{iNOS}^{-/-}$mice of $>1$ year. By contrast, ADAM12
\end{abstract}

Correspondence to: Professor Gerburg Keilhoff, Institute of Biochemistry and Cell Biology, Otto-von-Guericke University, Leipziger Straße 44, Magdeburg D-39120, Germany

E-mail: gerburg.keilhoff@med.ovgu.de

Key words: a disintegrin and metalloproteinase, endothelial nitric oxide synthase, neuronal nitric oxide synthase, inducible nitric oxide synthase, cortex, hippocampus expression was lowest in adult $\mathrm{nNOS}^{-/}$mice. Inhibition of NOS using $\mathrm{N}^{\omega}$-Nitro-L-arginine methyl ester hydrochloride, induced ADAM12 mRNA expression in N9 and PC12 cell lines. Inhibition of NOS using L-N $\mathrm{N}^{6}$-(1-Iminoethyl)lysine dihydrochloride, induced ADAM12 mRNA expression in N9 and C6 cell lines. No change in ADAM12 expression was observed in OLN93 cells following NOS inhibition. ADAM12 expression in mouse hippocampus and cortex samples demonstrated considerable variation during development, with a marked increase observed in adult and $>1$ year old mice, compared with that in fetal and neonatal mice.

\section{Introduction}

Nitric oxide (NO) is an important signaling molecule found in animals, including humans. Reduced NO production is associated with important cardiovascular risk factors, such as hyperlipidemia $(1,2)$, diabetes, hypertension, smoking, atherosclerosis and aging (3). The bioavailability of NO in cells and tissues decreases with age. This may be a result of a decrease in the expression of the constitutive isoforms [endothelial nitric oxide synthase (eNOS) and neuronal NOS (nNOS)], with age (4). Inducible NOS (iNOS)-mediated NO formation has been shown to affect longevity. In mice, iNOS overexpression may lead to increased mortality, which is associated with cardiac hypertrophy and sudden cardiac death as a result of bradyarrhythmias (5). iNOS expression is typically not observed in the brains of young (1-3 months old) animals and its expression increases with age (6). Furthermore, it has been shown that in the brain superoxides combine with $\mathrm{NO}$ to form peroxynitrite, thereby reducing the bioavailability of NO (7). Age-associated impairment of macrophage function is associated with a substantial decrease in iNOS levels in the immune system (8).

In the healthy nervous system, NO contributes, with other molecules, to learning and memory; synaptic activity; neural plasticity, including neurogenesis and cell survival; and cell differentiation. NO is associated with neurodegeneration, neuroinflammation and pathophysiological conditions, such as Alzheimer's disease, amyotrophic lateral sclerosis, Parkinson's disease, multiple sclerosis, Huntington's disease $(9,10)$ and brain tumors. 
NO activity has been extensively studied in tumor biology (11-28). It appears to be involved in all phases of carcinogenesis (12). Tumoricidal and tumor-promoting effects of NO have been observed, which depend on the type of cancer and the availability of NO (13). eNOS-derived NO has been shown to enhance angiogenesis in gliomas (14). Low grade gliomas demonstrate constitutive expression of eNOS in vessel endothelial cells and astrocytes, whereas malignant gliomas demonstrate overexpression of eNOS in aberrant vessels (15). Furthermore, studies have demonstrated that eNOS-deficient $\left(\mathrm{eNOS}^{-/}\right)$mice may be resistant to chemical carcinogenesis (16) and platelet-derived growth factor-induced gliomagenesis (17). eNOS inhibition was shown to lead to a decrease in tumor neovascularization, vascular permeability and tumor growth, in a number of carcinoma models $(18,19)$. Furthermore, increased nNOS expression has been observed in glial neoplasms. The highest nNOS values were observed in world health organization (WHO) grade III and IV tumors, and in carcinoma and melanoma metastasic tissues, whereas no or low nNOS expression was observed in WHO grade I or II tumors, and in meningiomas $(20,21)$. iNOS expression is induced in different types of human brain tumors, including gliomas (22), where it is known to promote glioma stem cell proliferation and tumor growth (23). Therefore, the inhibition of iNOS expression may be a useful therapeutic approach for the suppression of local cancer growth $(11,24)$.

Studies have suggested that NO donors may exhibit antiglioma (25) or antileukemic (26) effects. Evidence from previous studies indicates that NOS knockout may induce tumor development and progression $(27,28)$. NO is referred to as a 'double-edged sword' for a number of reasons: The three NOS isoforms show different spatial and temporal expression patterns; the levels of NO production are variable, depending on its (sub-)cellular source; NO may cause either cell death or proliferation; and, depending on its concentration, NO may exhibit anti- or pro-inflammatory activity.

As with NOS isoforms, studies have shown that members of the matrix metalloproteinase (MMP) family and a disintegrin and metalloproteinase domain-containing proteins (ADAMs) are overexpressed in high-grade glioma. Glioma-associated proteins include MMP-1, MMP-11, MMP-19 (29,30) and ADAM12 (31). These extracellular matrix degrading enzymes are associated with the fatal invasive capacity of high grade gliomas $(32,33)$. Furthermore, ADAM12 determines the localization, and promotes the activation, of MMP-14 (34).

It is hypothesized that ADAM12 and NO may act synergistically. NO suppresses MMP-9 expression by destabilizing its mRNA in rat mesangial cells (35), whereas inhibition of NOS has been found to promote cytokine-induced MMP-9 expression in aortic smooth muscle cells (36) and exotoxin-mediated MMP expression in iNOS $^{-/}$mice (37). Furthermore, NO may inhibit hypoxia-induced expression of ADAM10 (38). Therefore, it is hypothesized that NO may affect the expression of other ADAMs, including ADAM12. The present study analyzed ADAM12 expression levels in the cortex and hippocampus of wild-type mice, and in $\mathrm{eNOS}^{-/}, \mathrm{nNOS}^{-/}$and iNOS $^{-/}$mice, at different stages of development. For NO production, an age dependency is clear, however concerning ADAM12 expression in aged animals, available data are rare and limited to the musculature only (39).
ADAM12 belongs to a subgroup of the ADAM family, consisting of ADAM8, ADAM9, ADAM10, ADAM17 and ADAM19. They are cell-surface glycoproteins, containing metalloprotease, disintegrin (Arg-Gly-Asp-binding motif), cysteine-rich and epidermal growth factor(EGF)-like domains, and they are responsible for the release of the extracellular parts of membrane-bound proteins (shedding). Two splice variants of ADAM12 occur in humans: Membrane-anchored (ADAM12L) and cytoplasmic secreted (ADAM12S) (40). ADAM12 is proteolytically active in vitro and in vivo. ADAM12 may cause the shedding of pro heparin-binding-EGF (proHB-EGF), insulin-like growth factor-binding protein 3 (IGFBP-3), IGFBP-5 and oxytocinase (41). Recently, ADAM12 has been associated with ectodomain shedding of endothelial proteins in tumor vasculature (42). A consensus sequence that is required for, or facilitates, ADAM12 cleavage remains to be identified (43). The cytoplasmic tail of ADAM12 is one of the longest observed among the ADAMs (179 amino acids). It appears to be involved in the regulation of ADAM12 cellular localization (44). The cytoplasmic domain of ADAM12 contains a number of proline-rich motifs that are putative Src homology 3 (SH3) binding sites, which enable the recruitment of adapter molecules and subsequent activation of cellular signaling pathways. In addition, the cytoplasmic domain may contain one potential tyrosine phosphorylation site (SH2-binding site) and several serine/threonine phosphorylation sites (40). The following cytoplasmic binding partners have been identified for ADAM12: Src, proto-oncogene tyrosine-protein kinase Yes, growth factor receptor-bound protein 2, phosphoinositide 3-kinase, $\alpha$-actinin-1, $\alpha$-actinin-2, protein kinase $\mathrm{C} \Delta$, fluorescence in situ hybridization and protein kinase $\mathrm{C}$, and casein kinase substrate in neurons protein $3(40,41)$. Cytoplasmic binding sites may influence the maturation, trafficking, membrane (raft) localization and proteolytic activity of ADAMs.

In the early stages of mouse development, ADAM12 mRNA expression is prominent in mesenchymal cells, which develop into skeletal muscle, bone and visceral organs (45). ADAM12 mRNA may be detected at $>10.5$ DNA protein cross-link levels. It was originally reported to exhibit a restricted expression pattern in adult tissues, and the highest levels of ADAM12 expression have been observed in bone tissue samples (46). More recently, it has been shown that ADAM12 is ubiquitously expressed in adult mice. Studies have demonstrated that ADAM12 expression in mouse brain is predominantly, yet not exclusively, observed in oligodendrocytes $(47,48)$.

\section{Materials and methods}

Mice. Experiments were performed in accordance with the recommendations of and was approved by the Commission for Animal Care of the State of Saxony-Anhalt (Dessau, Germany) and German law of the Protection of Animals (permit number: 42502-2783 UniMD). The present study was conducted with laboratory-bred mice. Mice (C57BL/6 and wild-type control strains) were obtained from the homozygous institute breeding colony. $\mathrm{nNOS}^{-/}$mice were provided by the Hunag Lab $(49,50)$, eNOS$^{-/-}$mice were provided by the Gödecke Lab (51), iNOS ${ }^{-/-}$mice were obtained from Charles River Laboratories (Sulzfeld, Germany) as developed in the 
C57BL/6 strain (Charles River Laboratories) and their wildtype control strains. Animals were housed at $21^{\circ} \mathrm{C}$, exposed to a $12 \mathrm{~h}$ light and darkness cycle with access to food and water, ad libitum. Tissue from fetal, neonatal (5 days postnatal), adult (12 weeks old) and $>1$ year old mice was used, whereby the $>1$ year group consisted of animals aged between 12 and 18 months old. ( $n=3$ per age group).

Tissue preparation. In order to minimize circadian influences on the expression of hypothalamic peptides, mice were sacrificed between 09:00-09:30 h. Mice were anesthetized using isoflurane (Baxter GmbH Deutschland, Unterschleißheim, Germany). Subsequently, the mice were subjected to perfusion through the left ventricle for $30 \mathrm{sec}$, with $0.1 \mathrm{M}$ phosphate-buffered saline (PBS; pH 7.4; Sigma-Aldrich, Heidelberg, Germany) and then at $15 \mathrm{ml} / \mathrm{min}$ with $250 \mathrm{ml} 4 \%$ buffered paraformaldehyde (pH 7.4; PFA; Sigma-Aldrich). Brains were removed and post-fixed in $4 \%$ buffered PFA overnight at room temperature. The brains were subjected to cryoprotection for 2 days using $20 \%$ sucrose in $0.4 \%$ buffered PFA (pH 7.4) and embedded in paraffin. Brain coronal sections $(10 \mu \mathrm{m})$ were prepared using a sliding microtome (SM2010 R, Leica, Bensheim, Germany). Tissue samples were obtained from mice ( $n=10$ per age group) that had not been subjected to perfusion and were directly frozen in liquid nitrogen $\left(-80^{\circ} \mathrm{C}\right)$, in order to conduct reverse transcription-quantitative polymerase chain reaction (RT-qPCR) and immunoblot analyses.

Cell cultures. The following cell lines, representing the four main cell types in the brain, were used in the experiments: N9 mouse microglia cell line, [Ricciardi-Castagnioli lab (52)], C6 rat astroglia [CCL-107 ${ }^{\mathrm{TM}}$; American Type Culture Collection (ATCC), Manassas, VA, USA], OLN-93 rat oligodendroglial [Richter-Landsberg lab (53)] and rat neuronal PC12 (CRL-1721 ${ }^{\mathrm{TM}}$; ATCC). Cryopreserved cells were defrosted, resuspended in an RPMI 1640 medium (Sigma-Aldrich) supplemented with $10 \%$ fetal bovine serum, $1 \%$ L-glutamine, $50 \mathrm{U} / \mathrm{ml}$ penicillin and $50 \mu \mathrm{g} / \mathrm{ml}$ streptomycin (Life Technologies GmbH, Darmstadt, Germany), and transferred to culture flasks (Sarstedt, Nümbrecht, Germany). Following 3 days of incubation, cells were removed from the flasks by gentle agitation and incubated on poly-D-lysine coated Ø35-mm petri dishes (Sarstedt; 50,000 cells/dish), for 6 days. Subsequently, the respective experiments were performed, using the following NOS inhibitors: L-N $\mathrm{N}^{6}$-(1-Iminoethyl)lysine dihydrochloride (L-NIL; $0.5 \mathrm{mM}$; specific inhibitor of iNOS), $\mathrm{N}^{\omega}$-Nitro-L-arginine methyl ester hydrochloride (L-NAME; $0.5 \mathrm{mM}$; inhibitor of nNOS and eNOS, to lesser extent also of iNOS) and asymmetric dimethylarginine (ADMA; $10 \mu \mathrm{M}$; specific inhibitor of eNOS) all for $24 \mathrm{~h}$, all from SigmaAldrich. Cultures were maintained at $37^{\circ} \mathrm{C}$ in a humidified $5 \%$ $\mathrm{CO}_{2}$ atmosphere and the medium was changed every other day.

Immunoblot analysis of ADAM12. Frozen tissue samples were pulverized in liquid nitrogen and subsequently homogenized in lysis buffer (50 mM Tris/HCl, pH 7.5, 5 mM EDTA, $100 \mathrm{mM}$ $\mathrm{NaCl}, 0.5 \%$ Triton X-100, $10 \%$ glycerol, $10 \mathrm{mM} \mathrm{K}_{2} \mathrm{HPO}_{4}$ and $0.5 \%$ NP-40; all from Sigma-Aldrich), containing a protease inhibitor cocktail (Boehringer, Mannheim, Germany), $1 \mathrm{mM}$ sodium vanadate, $0.5 \%$ deoxycholate, $0.1 \mathrm{mM}$ phenylmethanesulfonylfluoride, $20 \mathrm{mM} \mathrm{NaF}$, and $20 \mathrm{mM}$ glycerol 2-phosphate (Sigma-Aldrich). Tissue homogenates were centrifuged at $15,000 \mathrm{x} \mathrm{g}$ for $15 \mathrm{~min}$ and the resulting supernatant was stored at $-20^{\circ} \mathrm{C}$.

Extracted proteins (30 $\mu \mathrm{g}$ per lane) were separated using $10 \%$ SDS-PAGE and transferred to nitrocellulose membranes (Schleicher and Schuell BioScience GmbH, Dassel, Germany). Membranes were blocked using 1 x Roti-block solution (Carl Roth, Karlsruhe, Germany) and then incubated with a primary antibody against ADAM12 cytoplasmic domain (AB19032; 1:1,000 dilution, affinity isolated, polyclonal, anti-rabbit; Merck Millipore, Darmstadt, Germany) diluted in PBS $(0.1 \%)$ buffer with Tween $-20^{\circledR}$ in bovine serum albumin (BSA; 5\%; Sigma-Aldrich, Hofheim, Germany). Subsequently, the blots were washed three times in PBS (0.3\%) with Tween-20 and then polyclonal horseradish peroxidase-conjugated anti-rabbit antibodies (\#7074; 1:2,000 dilution with 1 x Roti-Block; Cell Signaling Technology, Frankfurt, Germany) were applied. The SuperSignal West Dura Extended Duration substrate (Pierce Biotechnology, Inc., Rockford, IL, USA) was used in order to detect chemiluminescence. In order to compare groups, densitometric quantification was performed on equally processed blots that had been exposed to the same X-ray film [CEA (Deutschland) GmbH, Hamburg, Germany].

RNA extraction and RT-qPCR analysis of ADAM12 expression. Total RNA from cortical and hippocampal tissue samples was extracted using a two-step protocol using a TRIzol $^{\circledR}$ extraction (Invitrogen Life Technologies, Carlsbad, CA, USA) and the RNeasy kit ${ }^{\mathrm{TM}}$ (Qiagen, Hilden, Germany) according to a previous study (54). Tissue samples were frozen in liquid nitrogen and subsequently stored in $0.5 \mathrm{ml}$ TRIzol at $-80^{\circ} \mathrm{C}$. Tissue samples were then homogenized using DSTROY-S pistils (Biozym Scientific GmbH, Oldendorf, Germany) by subjecting the sample to 3-5 freezing (using liquid nitrogen; $-195^{\circ} \mathrm{C}$ ) and thawing (using an ice bath; $0^{\circ} \mathrm{C}$ ) cycles. After complete homogenization, $0.2 \mathrm{ml}$ chloroform was added, and the mixture was extensively vortexed and centrifuged using a microcentrifuge $\left(12,000 \mathrm{x} \mathrm{g}, 4^{\circ} \mathrm{C}\right)$ for $15 \mathrm{~min}$. The supernatant was incubated with isopropanol (volume ratio 1:1) at room temperature for $10 \mathrm{~min}$, and the precipitated RNA was obtained by centrifugation $\left(12,000 \mathrm{x} \mathrm{g}, 4^{\circ} \mathrm{C}, 10 \mathrm{~min}\right)$. The RNA pellet was resolved in $100 \mu \mathrm{l}$ RNase-free water and subsequently purified using the RNeasy kit, according to the manufacturer's instructions. Finally, the RNA was eluted in $50 \mu 1$ RNase-free water, confirmed using gel electrophoresis, and $5 \mu \mathrm{l}$ of RNA was used to measure the concentration of the RNA samples via ultraviolet spectroscopy (NanoDrop 2000c; Thermo Fisher Scientific, Wilmington, DE, USA).

For the cell lines, RNA was isolated using the innuPREP RNA isolation kit (Analytik Jena, Jena, Germany), as described previously (55).

Total RNA $(1 \mu \mathrm{g})$ was transcribed to a final volume of $40 \mu \mathrm{l}$ using 20 units of avian myeloblastosis virus reverse transcriptase (Promega GmbH, Mannheim, Germany), containing $1 \mathrm{x}$ reaction buffer, $0.5 \mathrm{mM}$ dNTP (Roche Diagnostics $\mathrm{GmbH}$, Mannheim, Germany), $10 \mathrm{mM}$ random hexanucleotides and 50 units of placenta RNase inhibitor (Promega $\mathrm{GmbH}$ ). The samples were incubated at $42^{\circ} \mathrm{C}$ for $1 \mathrm{~h}$. Subsequently enzymes 
were inactivated at $95^{\circ} \mathrm{C}$ for $10 \mathrm{~min}$ and the reaction mixture was frozen at $-80^{\circ} \mathrm{C}$, prior to enzymatic amplification.

ADAM12 transcript levels were determined using RT-qPCR with an iCycler (Bio-Rad, Munich, Germany) and the SensiMix ${ }^{\mathrm{TM}}$ dT kit (Bioline $\mathrm{GmbH}$, Luckenwalde, Germany). The PCR reaction mixture $(25 \mu \mathrm{l})$ consisted of $12.5 \mu \mathrm{l}$ of $2 \mathrm{x}$ concentrated master mix (SensiMix ${ }^{\mathrm{TM}}$; Bioline $\mathrm{GmbH}), 2 \mu \mathrm{l}$ RT-reaction and $0.25 \mu \mathrm{M}$ reverse and forward primers for ADAM12, large ribosomal protein p0 (RPLP0) or 60S ribosomal protein L13a (RPLP13a). The latter two primers were used for standardization. The following PCR protocol was performed: Initial denaturation and activation at $95^{\circ} \mathrm{C}$ for $10 \mathrm{~min}$, followed by 40 cycles of denaturation at $94^{\circ} \mathrm{C}$ for $15 \mathrm{sec}$, annealing at $60^{\circ} \mathrm{C}$ for $20 \mathrm{sec}$ and elongation at $72^{\circ} \mathrm{C}$ for $30 \mathrm{sec}$. Fluorescence intensity of the double-stranded specific SYBR-Green I, reflecting the quantity of PCR-product, was measured (CFX96 Thermocycler; Bio-Rad) at the end of each elongation step. Correlation coefficients of all three standard curves were $>0.95$. Final results are expressed as artificial units. RPLP0 and RPLP13a expression levels were used to normalize the cDNA contents. In order to verify the size of the PCR product, samples were separated on $1.8 \%$ agarose gels and stained with ethidium bromide. The following primers, which were designed using the Invitrogen OligoPerfect Designer and obtained from Invitrogen Life Technologies were used for the RT-qPCR analysis: Forward: 5'-GCACTCTCgCTT TCTGGAGGGTGT-3' and reverse: 5'-TGACTTGGTTGC TTTGGCGGGATT-3' for mouse RPLP0 (344 bp), forward: 5'-CTGGTACTTCCACCCGACCTC-3' and reverse: 5'- GGA TCCCTCCACCCTATGACA-3' for rat RPLP13a (131 bp), forward: 5'-CAGCAACTCCTGTGACCTCC-3' and reverse: 5'-GTACCAATGACAGGTCGGCT-3' for mouse ADAM12 (333 bp) and forward: 5'-GCTTGCAGGAACCAAGTG TG-3' and reverse: 5'-CTGGTTATCTGCTTGCCGGA-3' for rat ADAM12 (226 bp).

Immunohistochemistry. ADAM12 immunoreactive material was immunolocalized using a rabbit polyclonal antiserum against the appropriate peptide sequence (1:200 dilution; SA-378; Biomol GmbH, Hamburg, Germany) and a nickel-amplified avidin-biotin technique, as previously described (47). The sections were incubated with methanol and $\mathrm{H}_{2} \mathrm{O}_{2}$ in order to suppress endogenous peroxidases. Subsequently, they were repeatedly washed with PBS and the primary antiserum was then applied. The immunohistochemical protocol used an avidin-biotin method and a vectastain-peroxidase kit (Camon, Wiesbaden, Germany), using 3,3'-diaminobenzidine as chromogen. The color reaction was enhanced by adding $2 \mathrm{ml}$ of a $0.5 \%$ nickel ammonium sulfate solution, which yields a dark purplish-blue reaction product. Specific antibodies were replaced with buffer solution or normal rabbit serum (both from Sigma-Aldrich) for the control samples. Pre-absorption of the antiserum was performed using a peptide in order to produce the antiserum, according to the methods described in a previous study (47).

Statistical analysis. Data from brain tissue experiments were analyzed using Microcal Origin ${ }^{\mathrm{TM}}$ version 6.0 (OriginLab Corporation; Northampton, MA, USA). A Mann-Whitney test was used for the evaluation of ADAM12 expression.
For statistical analysis of the culture experiments, GraphPad Prism ${ }^{\circledR} 6.0$ program package (Graphpad Software, Inc., La Jolla, CA, USA) was used. A Kolmogorov-Smirnov-Test was conducted in order to check that the results were normally distributed, and a one-way analysis of variance was performed in order to compare groups. Significant interactions were investigated using Tukey's post hoc test. $\mathrm{P}<0.05$ was considered to indicate a statistically significant difference.

\section{Results}

Localizations of ADAM12 expression. In the wild-type mouse brain samples, ADAM12 immunoreactivity was observed almost exclusively in oligodendrocytes (Fig. 1A). Oligodendrocytes were also the predominant cell type to express ADAM12 in $\mathrm{eNOS}^{-/-}$and $\mathrm{nNOS}^{-/-}$mouse brain samples (Fig. $1 \mathrm{~B}$ and $\mathrm{C} ; \mathrm{P}>0.05$ vs. wild-type). In addition to oligodendroglial cells, a number of neurons were observed to be ADAM12 immunoreactive in $\mathrm{eNOS}^{-/-}$(Fig. 1D) and nNOS $^{-/-}$(Fig. 1E) mouse brain samples. By contrast, ADAM12 immunopositivity was observed less frequently in neurons $\left(\mathrm{P}<0.001\right.$ vs. $\mathrm{nNOS}^{-/-} ; \mathrm{P}<0.002$ vs. $\left.\mathrm{eNOS}^{-/-}\right)$, astrocytes and blood vessel endothelial cells of wild type mice (Fig. 1F).

ADAM12 mRNA expression in the cortex and hippocampus of wild type mice. RT-qPCR analysis was conducted in order to investigate the expression levels of ADAM12 in the cortex and hippocampus of wild-type mice. An increase in ADAM12 mRNA expression was observed with increasing age. The highest levels of ADAM12 mRNA expression were observed in the hippocampus of adult mice (Fig. 2).

Expression of ADAM12 in the cortex of wild-type and $\mathrm{NOS}^{-/}$mice. In order to verify the age-associated changes in ADAM12 mRNA expression levels, immunoblot analyses were performed. Mature (90 kDa) ADAM12 was detected in the cortex of wild-type C57/BL6 mice, at all ages. In accordance with the mRNA expression data, protein expression was low in the cortex of fetal and neonatal mice. By contrast, a markedly increased level of ADAM12 expression was observed in adult and $>1$ year old mice. A similar increase in ADAM12 expression with age was observed in the cortex of $\mathrm{nNOS}^{-/}, \mathrm{iNOS}^{-/-}$and eNOS $^{-/-}$mice. However, in adult mice of the latter genotype, a tendency for ADAM12 expression levels to remain below those of wild-type mice was observed $(\mathrm{P}>0.05)$. Likewise, iNOS $^{-/}$mice $>1$ year old exhibited a tendency towards reduced levels of ADAM12 expression compared with wild-type mice $(\mathrm{P}<0.1)$ (Fig. 3).

Expression of ADAM12 in the hippocampus of wild-type and $\mathrm{NOS}^{-/}$mice. As with ADAM12 expression levels in the cortex, mature $(90 \mathrm{kDa})$ ADAM12 expression was observed in the hippocampus of mice of all ages and genotypes. A marked increase in ADAM12 expression was observed in adult and mice $>1$ year old, compared with that in fetal and neonatal mice. There was a tendency towards increased levels of mature ADAM12 in iNOS $^{-/-}$mice and reduced expression in $\mathrm{eNOS}^{-/-}$ and $\mathrm{nNOS}^{-/-}$mice when compared with wild-type mice $(\mathrm{P}<0.1$; Fig. 4). 

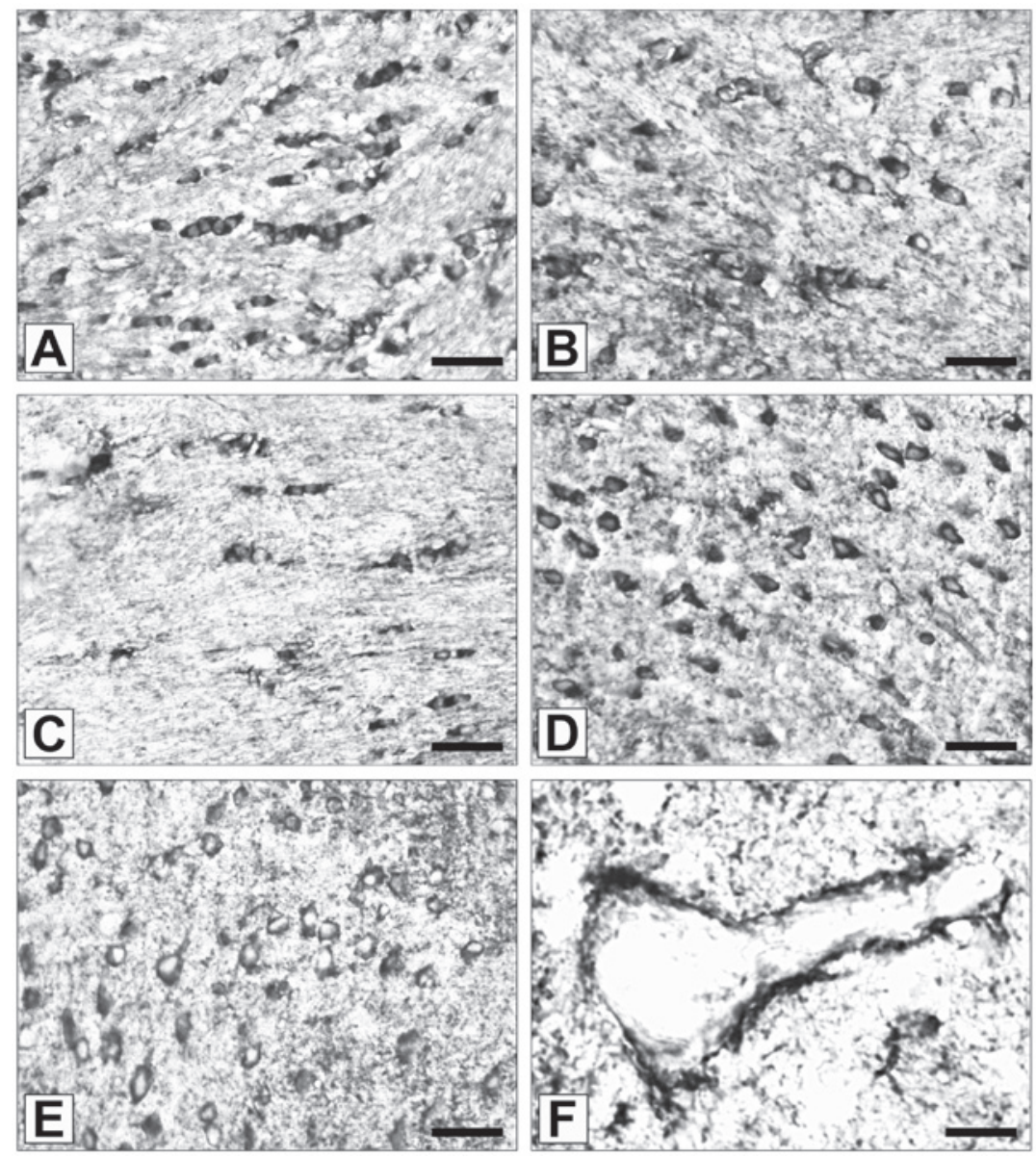

Figure 1. Cellular expression of ADAM12 in brain samples from representative wild-type, nNOS ${ }^{-/}$and eNOS ${ }^{-/}$mice. (A) Wild-type mouse. A number of parafascicular oligodendrocytes exhibit ADAM12 immunopositivity. Bar $=20 \mu \mathrm{m}$. (B) ADAM12-expressing parafascicular oligodendrocytes in an eNOS ${ }^{-/-}$mouse brain sample. Bar $=15 \mu \mathrm{m}$. (C) ADAM12-expressing parafascicular oligodendrocytes in an nNOS ${ }^{-/-}$mouse brain sample. In the upper left corner an ADAM12 immunoreactive astrocyte is visible. Bar $=20 \mu \mathrm{m}$. (D) Cluster of immunostained neurons in an eNOS ${ }^{-/-} \mathrm{mouse}_{\mathrm{brain}} \mathrm{sample}$. Bar=30 $\mu \mathrm{m}$. (E) Cluster of immunostained neurons in the brain of an $\mathrm{nNOS}^{-/}$mouse brain sample. Bar $=30 \mu \mathrm{m}$. (F) A cerebral microvessel surrounded by ADAM12 immunoreactive astrocytic end-feet and an ADAM12-expressing astrocyte in a wild-type mouse brain sample. iNOS ${ }^{-/}$was not included in this figure as the structure preservation was unsatisfactory. ADAM12 immunoreactive neurons were rarely observed in wild-type mice. Bar=15 $\mu$ m. ADAM12, a disintegrin and metalloproteinase domain-containing protein $12 ; \mathrm{nNOS}^{-/-}$, neuronal nitric oxide synthase-deficient; $\mathrm{NOS}^{-/-}$, endothelial nitric oxide synthase-deficient.

Effects of pharmacological inhibition of NOS on ADAM12 expression in glial cell lines. The N9 microglial cell line was exposed to the following NOS inhibitors: L-NIL, L-NAME and ADMA for $24 \mathrm{~h}$. Subsequently, ADAM12 mRNA expression in N9 cells was determined using RT-qPCR. NOS inhibition using L-NIL and L-NAME $(0.5 \mathrm{mM})$ led to a significant increase in ADAM12 mRNA expression levels compared with the controls $(300 \pm 50 \%, \mathrm{P}<0.05$ and $400 \pm 50 \%$, $\mathrm{P}<0.03$, respectively; Fig. 5A). NOS inhibition using ADMA at $10 \mu \mathrm{M}$ led to a significant, 2-fold increase in ADAM12 mRNA expression in N9 cells, compared with that in the control cells $(\mathrm{P}<0.02)$.

The effects of pharmacological NOS inhibition on ADAM12 expression in the PC12 neuronal cell line was then investigated. In the PC12 cell line, inhibition of NOS using L-NAME, significantly increased ADAM12 mRNA expression, compared with that of the controls $(173 \pm 25 \%, \mathrm{P}<0.05)$. By contrast, no differences were observed in ADAM12 mRNA expression levels between PC12 cells treated with L-NIL or ADMA, and those in the control cells (Fig. 5B).

ADAM12 mRNA expression in rat OLN93 cells was not affected by L-NAME, L-NIL nor ADMA treatment, compared

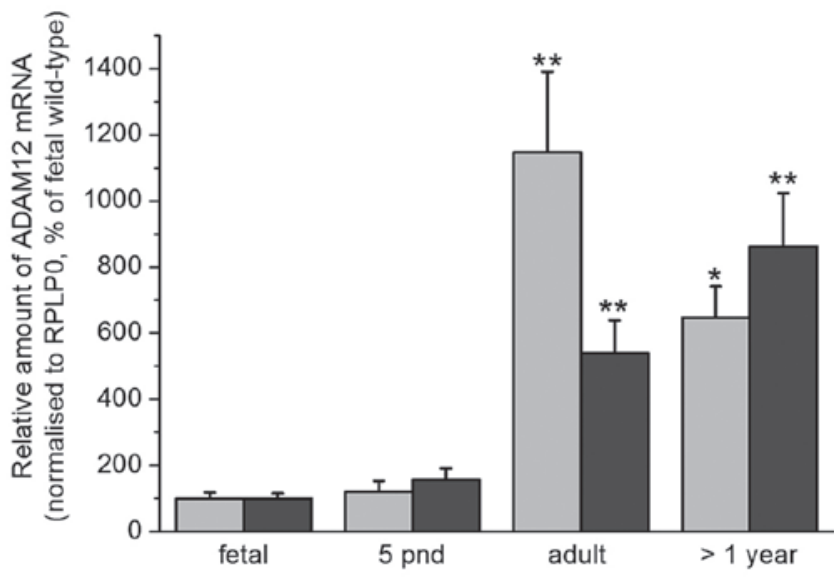

Figure 2. ADAM12 mRNA expression in brain samples from wild-type mice increases with age. Hippocampal (grey) and cortical (black) ADAM12 mRNA expression levels were assessed using reverse transcription-quantitative polymerase chain reaction in fetal, neonatal, adult and $>1$ year old mice. Expression levels were normalized to large ribosomal protein p0 (mouse) mRNA. Relative values with fetal expression levels set to $100 \%$ (mean \pm standard error, $n=8$ ) ${ }^{*} \mathrm{P}<0.05$ and ${ }^{* * *} \mathrm{P}<0.01$ vs. fetal group. ADAM12, a disintegrin and metalloproteinase domain-containing protein 12 ; pnd, postnatal days. 

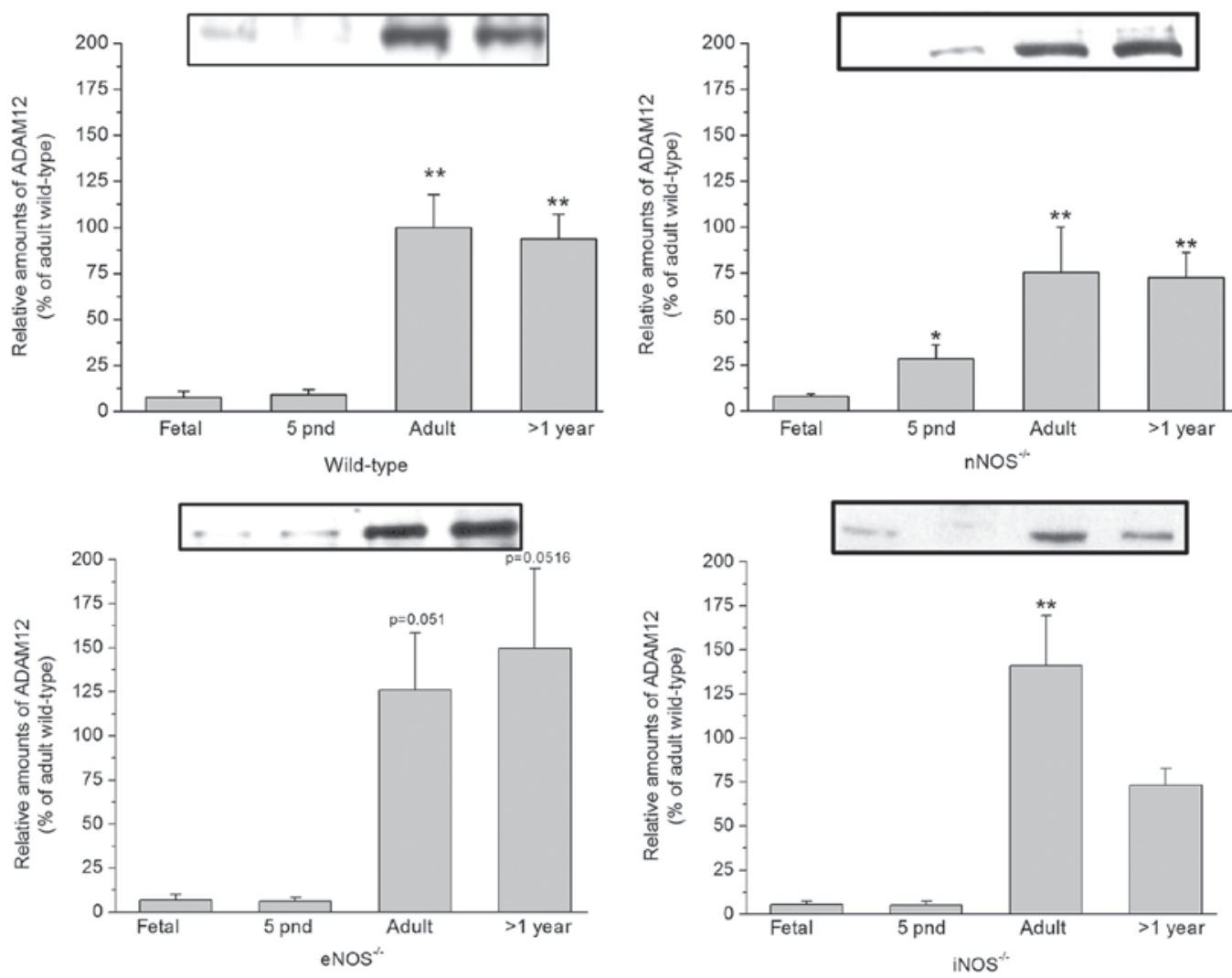

Figure 3. ADAM12 expression in the cortex of wild-type (top left), $\mathrm{nNOS}^{-/-}$(top right), $\mathrm{eNOS}^{-/}$(bottom left) and iNOS ${ }^{-/}$(bottom right) mice at different ages, assessed using immunoblot analysis. Data are presented relative to that of adult wild-type mice, standardized to $100 \%$ (mean \pm standard error, $\mathrm{n} \geq 6$ ). ${ }^{*} \mathrm{P}<0.05$ and ${ }^{* *} \mathrm{P}<0.01$ vs. fetal). ADAM12, a disintegrin and metalloproteinase domain-containing protein $12 ; \mathrm{nNOS}^{-/}$, neuronal nitric oxide synthase deficient; iNOS ${ }^{-/}$, inducible nitric oxide synthase deficient; $\mathrm{eNOS}^{-/}$, endothelial nitric oxide synthase deficient; pnd, postnatal days.
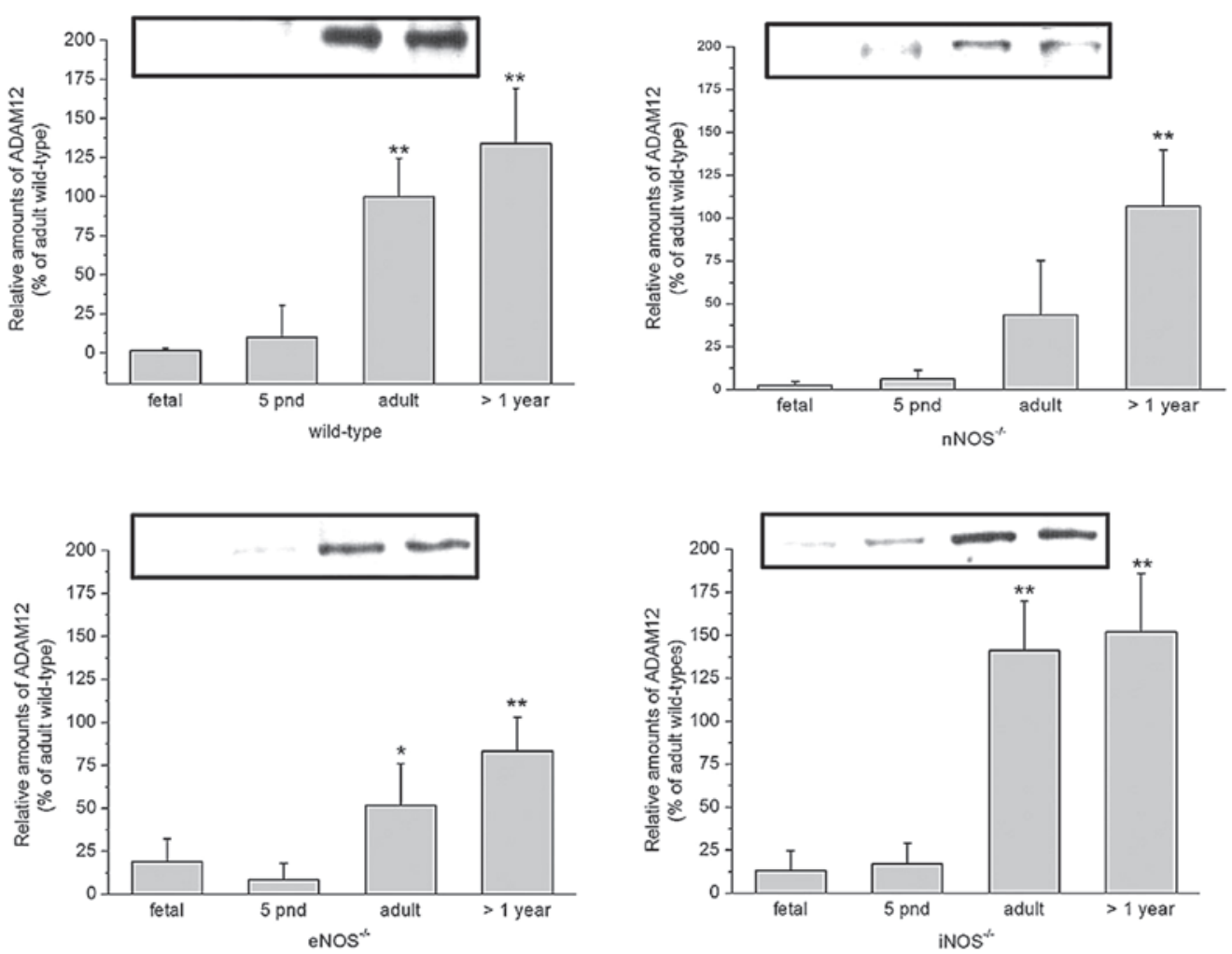

Figure 4. ADAM12 expression in the hippocampus of wild-type (top left), $\mathrm{nNOS}^{-/}$(top right), $\mathrm{eNOS}^{-/}$(bottom left) and iNOS ${ }^{-/}$(bottom right) mice at different age, as assessed using immunoblot analysis. Data are presented relative to that of adult wild-type mice, standardized to $100 \%$ (mean \pm standard error, $\mathrm{n} \geq 6$, "P $<0.05$ and $^{* *}<0.01$ vs. fetal). ADAM12, a disintegrin and metalloproteinase domain-containing protein $12 ; \mathrm{nNOS}^{--}$, neuronal nitric oxide synthase deficient; iNOS $^{-/}$, inducible nitric oxide synthase deficient; endothelial nitric oxide synthase deficient, eNOS ${ }^{-/}$; pnd, postnatal days. 
A

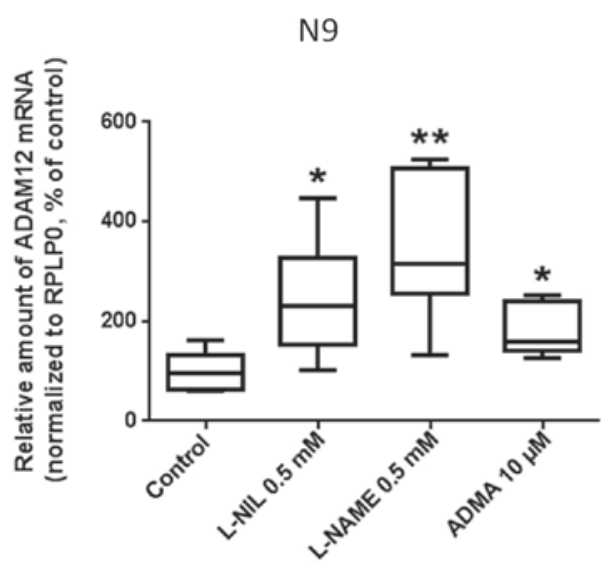

C

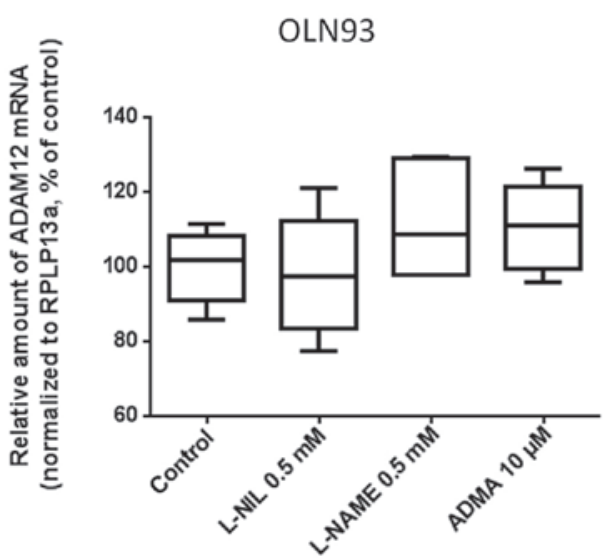

B

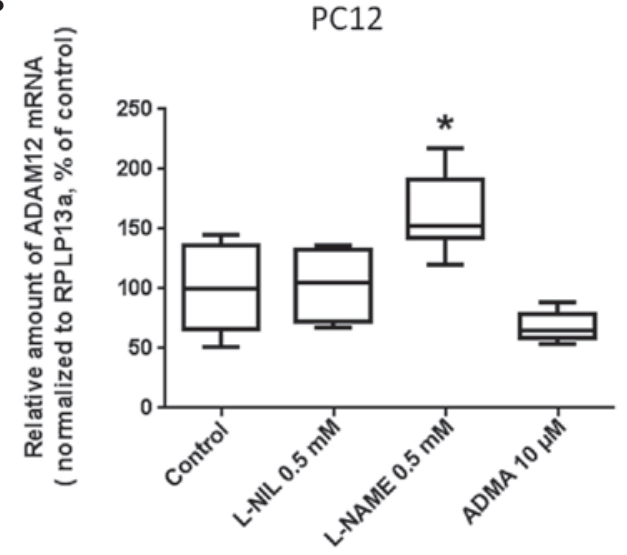

D

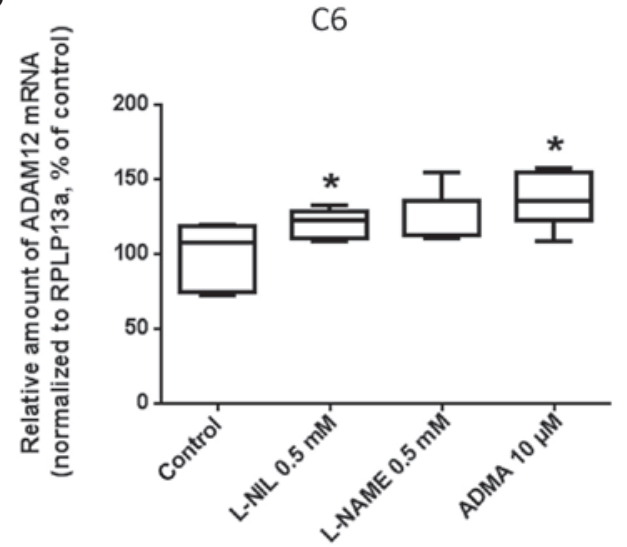

Figure 5. Effect of NOS-inhibition on ADAM12 mRNA expression in (A) N9 cells, (B) PC12 cells, (C) OLN93 cells and (D) C6 cells. Cells were exposed to NOS inhibitors at different concentrations for $24 \mathrm{~h}$ and ADAM12 mRNA levels were assessed using reverse transcription-quantitative polymerase chain reaction. Expression levels were normalized to that of large ribosomal protein p0 (mouse) or 60S ribosomal protein L13a (rat) mRNA levels, and the relative expression of control cells was set to $100 \%$. All data are provided as medians; boxes represent the first and third quartiles and whiskers represent the ranges. A Mann-Whitney-U test for unpaired group comparison was performed in order to determine any differences between the groups. $\left(\mathrm{n}=4\right.$; ${ }^{*} \mathrm{P}<0.05$ and ${ }^{* * *} \mathrm{P}<0.01$ vs. control). ADAM12, a disintegrin and metalloproteinase domain-containing protein 12; L-NIL, L-N6-(1-Iminoethyl)lysine dihydrochloride; L-NAME, $\mathrm{N}^{\omega}$-Nitro-L-arginine methyl ester hydrochloride; ADMA, asymmetric dimethylarginine.

with expression the control cells (Fig. 5C). Rat C6 glia cells exhibited increased ADAM12 mRNA expression in response to L-NIL and ADMA treatment, although not in response to L-NAME treatment (Fig. 5D). The efficacy of the NOS inhibitors was confirmed in pilot experiments by measuring the alterations in NO concentration using an NO-sensitive electrode (ISO-NO-METER; World Precision Instruments, Berlin, Germany) as described in (56).

\section{Discussion}

ADAMs exhibit a multi-domain structure and ectopeptidase activity, and are involved in the regulation of cell-matrix interactions and cell-cell communication. ADAM expression and activity has been linked to important functions, such as cell differentiation, proliferation, development and inflammation, and to tumor cell growth, invasion and metastasis. ADAM12 is a proteolytically active ADAM, and two isoforms are produced as a results of alternative splicing: The membrane-bound, ADAM12-L, and the shorter soluble form, ADAM12-S (57). Increased expression levels of ADAM12-L and ADAM12-S, have been observed in several types of cancer, including carcinoma of the breast, bladder and lung, and in glioblastoma (58). Urinary concentrations of ADAM12 have been shown to correlate with cancer stage, making it a potential biomarker with which to monitor tumor progression (59-61). ADAM12 facilitates tumor progression by stimulating cell proliferation and survival pathways (62-64). This is achieved by the proteolytic activation and release (ectodomain shedding) of membrane-bound growth factors, including HB-EGF, erythroblastic leukemia viral oncogene homolg 4, tumor necrosis factor $\alpha$ and tumor growth factor $\alpha(40,65)$.

In the present study, an increase in the expression of ADAM12 in the cortex and hippocampus samples from mice was observed was increasing age. In addition, ADAM12 expression levels were significantly higher in $\mathrm{eNOS}^{-/ \text {, }}$ $\mathrm{nNOS}^{-/-}$and iNOS $^{-/-}$adult, and mice $>1$ year old, compared with those in wild-type mice. The results of the present study suggest there may be an association between NOS activity and ADAM12 expression levels. In support of this view, an increased expression of ADAM12 was observed in response to NOS inhibition in murine N9 microglia, rat C6 astroglia and, to a lesser extent, in rat PC12 neuronal cells. By contrast, no induction of ADAM12 expression was observed in OLN93 
rat oligodendrocytes. Consistent with the predominant and apparently high constitutive expression of ADAM12 in oligodendrocytes $(47,48)$, it may be hypothesized that ADAM12 expression may not be subject to significant regulation, at least by NO, in oligodendrocytes. The association between ADAM12 and NOS isotype expression observed in the current study together with the known effects of NO on neural cell development (65), suggest that ADAM12 and NO are interdependently associated with neuronal development and function.

At the dosages applied in the present study, the NOS inhibitor L-NIL would be expected to inhibit iNOS activity, whilst eNOS activity remains largely unaffected. L-NAME would be expected to inhibit nNOS, eNOS and, to a lesser extent, iNOS activity. By contrast, ADMA $(10 \mu \mathrm{M})$ would be expected to inhibit eNOS activity, and not iNOS activity (66).

NO affects glutamatergic neurotransmission and is associated with the storage, uptake and/or release of a number of neurotransmitters in the central nervous system, such as acetylcholine, dopamine, noradrenaline, $\gamma$-aminobutyric acid, taurine and glycine $(64,65,67)$, as well as certain neuropeptides (68). Since NO is a highly diffusible molecule, it is capable of mediating synaptic and non-synaptic communication processes. Furthermore, NO is a free radical due to its unpaired electron $(\bullet \mathrm{NO})$. Therefore, it exhibits toxic effects at higher concentrations (69-72). NO toxicity is accentuated in the presence of oxidative radicals such as $\mathrm{O}^{2-}$, which may be generated by NOS when L-arginine substrate concentrations are low $(73,74)$. The aging process is also associated with increased nitrosative and oxidative damage (75). NO is involved in brain development by influencing synaptic plasticity and mediating the change from cell proliferation to differentiation during neurogenesis (76).

ADAM12 has been shown to cause shedding of the $\Delta$-like protein 1 ectodomain, thereby facilitating the activation of Notch signaling (77). In human umbilical vein endothelial (HUVEC) cells, the activation of Notch induces the expression of the NO receptor, soluble guanylyl cyclase heterodimer, guanylate cyclase 1 soluble $\alpha 3$ (GUCY1 $\alpha 3$ ) and GUCY1 $\beta 3$ (78). Phosphatidylinositol-3 kinase/protein kinase B-dependent phosphorylation/activation of eNOS was observed in HUVEC cells. Therefore, Notch signaling may induce NO production and NO-receptor expression in HUVEC cells. By contrast, downregulation of Notch1 has been shown to induce iNOS expression in a model of myocardial ischemia/reperfusion (79). iNOS-mediated NO production, together with the induction of the subunit of NADPH oxidase, gp91phox, and the resulting increase in superoxide anion production, is likely to contribute to increased infarct size and fibrosis via the enhanced formation of peroxynitrite (79)

It has recently been established that Notch signaling regulates the expression of ADAM12 (80). Therefore, it is hypothesized that there is an association between ADAM12 expression, Notch signaling and NOS/NO. The induction of ADAM12 in response to NOS-inhibition that was observed in the present study is in accordance with this hypothesis. However, the role of Notch signaling for ADAM12 expression requires further investigation.

In conclusion, the results of the present study demonstrate that cortical and hippocampal ADAM12 expression increases with mouse development and age. NOS-deficiency leads to increased ADAM12 expression in adult and 1-year old mice, compared with that in fetal and neonatal mice. However, the physiological and pathophysiological mechanisms underlying these patterns require further investigations.

\section{Acknowledgements}

The authors would like to thank Doris Treczak, Manja Möller, Ines Schultz and Leona Bück for their technical assistance. This study was supported by a grant from the Bundesministerium für Forschung und Technik (grant no. 01ZZ0407/PFG1).

\section{References}

1. Schild L, Dombrowski F, Lendeckel U, Schulz C, Gardemann A and Keilhoff G: Impairment of endothelial nitric oxide synthase causes abnormal fat and glycogen deposition in liver. Biochim Biophys Acta 1782: 180-187, 2008.

2. Schild L, Jaroscakova I, Lendeckel U, Wolf G and Keilhoff G: Neuronal nitric oxide synthase controls enzyme activity pattern of mitochondria and lipid metabolism. FASEB J 20: 145-147, 2006.

3. Torregrossa AC, Aranke M and Bryan NS: Nitric oxide and geriatrics: Implications in diagnostics and treatment of the elderly. J Geriatr Cardiol 8: 230-242, 2011.

4. Cau SB, Carneiro FS and Tostes RC: Differential modulation of nitric oxide synthases in aging: Therapeutic opportunities. Front Physiol 3: 218, 2012.

5. Mungrue IN, Gros R, You X, Pirani A, Azad A, Csont T, Schulz R, Butany J, Stewart DJ and Husain M: Cardiomyocyte overexpression of iNOS in mice results in peroxynitrite generation, heart block, and sudden death. J Clin Invest 109: 735-743, 2002.

6. Licinio J, Prolo P, McCann SM and Wong ML: Brain iNOS: Current understanding and clinical implications. Mol Med Today 5: 225-232, 1999 .

7. van der Loo B, Labugger R, Skepper JN, Bachschmid M, Kilo J, Powell JM, Palacios-Callender M, Erusalimsky JD, Quaschning T, Malinski T, et al: Enhanced peroxynitrite formation is associated with vascular aging. J Exp Med 192: $1731-1744,2000$

8. Mahbub S, Deburghgraeve CR and Kovacs EJ: Advanced age impairs macrophage polarization. J Interferon Cytokine Res 32: 18-26, 2012.

9. Bernstein HG, Keilhoff G, Steiner J, Dobrowolny H and Bogerts B: Nitric oxide and schizophrenia: Present knowledge and emerging concepts of therapy. CNS Neurol Disord Drug Targets 10: 792-807, 2011.

10. Keilhoff G: nNOS deficiency-induced cell proliferation depletes the neurogenic reserve. Neurosci Lett 505: 248-253, 2011.

11. Bian K, Ghassemi F, Sotolongo A, Siu A, Shauger L, Kots A and Murad F: NOS-2 signaling and cancer therapy. IUBMB Life 64: 676-683, 2012.

12. Choudhari SK, Chaudhary M, Bagde S, Gadbail AR and Joshi V: Nitric oxide and cancer: A review. World J Surg Oncol 11: 118, 2013.

13. Fukumura D, Kashiwagi S and Jain RK: The role of nitric oxide in tumour progression. Nat Rev Cancer 6: 521-534, 2006.

14. Wang Y, Yan W, Lu X, Qian C, Zhang J, Li P, Shi L, Zhao P, Fu Z, $\mathrm{Pu}$ P, et al: Overexpression of osteopontin induces angiogenesis of endothelial progenitor cells via the av $\beta 3 / \mathrm{PI} 3 \mathrm{~K} / \mathrm{AKT} / \mathrm{eNOS} / \mathrm{NO}$ signaling pathway in glioma cells. Eur J Cell Biol 90: 642-648, 2011.

15. Bulnes S, Argandoña EG, Bengoetxea H, Leis O, Ortuzar N and Lafuente JV: The role of eNOS in vascular permeability in ENU-induced gliomas. Acta Neurochir Suppl 106: 277-282, 2010.

16. Lim KH, Ancrile BB, Kashatus DF and Counter CM: Tumour maintenance is mediated by eNOS. Nature 452: 646-649, 2008.

17. Charles N, Ozawa T, Squatrito M, Bleau AM, Brennan CW, Hambardzumyan D and Holland EC: Perivascular nitric oxide activates notch signaling and promotes stem-like character in PDGF-induced glioma cells. Cell Stem Cell 6: 141-152, 2010.

18. Gratton JP, Lin MI, Yu J, Weiss ED, Jiang ZL, Fairchild TA, Iwakiri Y, Groszmann R, Claffey KP, Cheng YC, et al: Selective inhibition of tumor microvascular permeability by cavtratin blocks tumor progression in mice. Cancer Cell 4: 31-39, 2003. 
19. Giliano NY, Konevega LV and Noskin LA: Dynamics of intracellular superoxide and NO content in human endotheliocytes and carcinoma cells after treatment with NO synthase inhibitors. Bull Exp Biol Med 149: 78-81, 2010

20. Broholm H, Rubin I, Kruse A, Braendstrup O, Schmidt K, Skriver EB and Lauritzen M: Nitric oxide synthase expression and enzymatic activity in human brain tumors. Clin Neuropathol 22: 273-281, 2003.

21. Kostourou V, Cartwright JE, Johnstone AP, Boult JK, Cullis ER, Whitley G and Robinson SP: The role of tumour-derived iNOS in tumour progression and angiogenesis. Br J Cancer 104: 83-90, 2011.

22. Lam-Himlin D, Espey MG, Perry G, Smith MA and Castellani RJ: Malignant glioma progression and nitric oxide. Neurochem Int 49: 764-768, 2006.

23. Eyler CE, Wu Q, Yan K, MacSwords JM, Chandler-Militello D Misuraca KL, Lathia JD, Forrester MT, Lee J, Stamler JS, et al: Glioma stem cell proliferation and tumor growth are promoted by nitric oxide synthase-2. Cell 146: 53-66, 2011 .

24. Tatemichi M, Ogura T and Esumi H: Impact of inducible nitric oxide synthase gene on tumor progression. Eur J Cancer Prev 18: 1-8, 2009.

25. Kogias E, Osterberg N, Baumer B, Psarras N, Koentges C, Papazoglou A, Saavedra JE, Keefer LK and Weyerbrock A Growth-inhibitory and chemosensitizing effects of the glutathi one-S-transferase- $\pi$-activated nitric oxide donor PABA/NO in malignant gliomas. Int J Cancer 130: 1184-1194, 2012.

26. Bian H, Feng J, Li M and Xu W: Novel antileukemic agents derived from tamibarotene and nitric oxide donors. Bioorg Med Chem Lett 21: 7025-7029, 2011.

27. Mocellin S, Bronte V and Nitti D: Nitric oxide, a double edged sword in cancer biology: Searching for therapeutic opportunities. Med Res Rev 27: 317-352, 2007.

28. Cheng H, Wang L, Mollica M, Re AT, Wu S and Zuo L: Nitric oxide in cancer metastasis. Cancer Lett 353: 1-7, 2014

29. Stojic J, Hagemann C, Haas S, Herbold C, Kühnel S, Gerngras S Roggendorf W, Roosen K and Vince GH: Expression of matrix metalloproteinases MMP-1, MMP-11 and MMP-19 is correlated with the WHO-grading of human malignant gliomas. Neurosci Res 60: 40-49, 2008.

30. Pullen NA and Fillmore HL: Induction of matrix metalloproteinase- 1 and glioma cell motility by nitric oxide J Neurooncol 96: 201-209, 2010.

31. Kodama T, Ikeda E, Okada A, Ohtsuka T, Shimoda M, Shiomi T, Yoshida K, Nakada M, Ohuchi E and Okada Y: ADAM12 is selectively overexpressed in human glioblastomas and is associated with glioblastoma cell proliferation and shedding of heparin-binding epidermal growth factor. Am J Pathol 165: 1743-1753, 2004

32. Fillmore HL, VanMeter TE and Broaddus WC: Membrane-type matrix metalloproteinases (MT-MMPs): Expression and function during glioma invasion. J Neurooncol 53: 187-202, 2001.

33. Van Meter TE, Broaddus WC, Rooprai HK, Pilkington GJ and Fillmore HL: Induction of membrane-type-1 matrix metalloproteinase by epidermal growth factor-mediated signaling in gliomas. Neuro Oncol 6: 188-199, 2004.

34. Albrechtsen R, Kveiborg M, Stautz D, Vikeså J, Noer JB Kotzsh A, Nielsen FC, Wewer UM and Fröhlich C: ADAM12 redistributes and activates MMP-14, resulting in gelatin degradation, reduced apoptosis and increased tumor growth. J Cel Sci 126: 4707-4720, 2013

35. Akool el-S, Kleinert H, Hamada FM, et al: Nitric oxide increases the decay of matrix metalloproteinase $9 \mathrm{mRNA}$ by inhibiting the expression of mRNA-stabilizing factor HuR Mol Cell Biol 23:4901-4916, 2003

36. Knipp BS, Ailawadi G, Ford JW, Peterson DA, Eagleton MJ, Roelofs KJ, Hannawa KK, Deogracias MP, Ji B, Logsdon C, et al Increased MMP-9 expression and activity by aortic smooth muscle cells after nitric oxide synthase inhibition is associated with increased nuclear factor-kappaB and activator protein-1 activity. J Surg Res 116: 70-80, 2004.

37. Okamoto T, Gohil K, Finkelstein EI, Bove P, Akaike T and van der Vliet A: Multiple contributing roles for NOS2 in LPS-induced acute airway inflammation in mice. Am J Physiol Lung Cell Mol Physiol 286: L198-L209, 2004

38. Barsoum IB, Hamilton TK, Li X, Cotechini T, Miles EA, Siemens DR and Graham CH: Hypoxia induces escape from innate immunity in cancer cells via increased expression of ADAM10: Role of nitric oxide. Cancer Res 71: 7433-7441, 2011.
39. Jørgensen LH, Jensen CH, Wewer UM and Schrøder HD: Transgenic overexpression of ADAM12 suppresses muscle regeneration and aggravates dystrophy in aged mdx mice. Am J Pathol 171: 1599-1607, 2007.

40. Wever UM, Albrechtsen R and Engvall E: ADAM12 The long and the short of it. In: The ADAM Family of Proteases. Hooper NM and Lendeckel U (eds). Vol 4. Springer, Dordrecht, The Netherlands, pp123-146, 2005.

41. White JM: ADAMs: Modulators of cell-cell and cell-matrix interactions. Curr Opin Cell Biol 15: 598-606, 2003.

42. Fröhlich C, Klitgaard M, Noer JB, Kotzsch A, Nehammer C, Kronqvist P, Berthelsen J, Blobel C, Kveiborg M, Albrechtsen R, et al: ADAM12 is expressed in the tumour vasculature and mediates ectodomain shedding of several membrane-anchored endothelial proteins. Biochem J 452: 97-109, 2013.

43. Jacobsen J, Visse R, Sørensen HP, Enghild JJ, Brew K, Wewer UM and Nagase H: Catalytic properties of ADAM12 and its domain deletion mutants. Biochemistry 47: 537-547, 2008.

44. Hougaard S, Loechel F, Xu X, Tajima R, Albrechtsen R and Wewer UM: Trafficking of human ADAM 12-L: Retention in the trans-Golgi network. Biochem Biophys Res Commun 275: 261-267, 2000.

45. Kurisaki T, Masuda A, Osumi N, Nabeshima Y and Fujisawa-Sehara A: Spatially- and temporally-restricted expression of meltrin alpha (ADAM12) and beta (ADAM19) in mouse embryo. Mech Dev 73: 211-215, 1998.

46. Yagami-Hiromasa T, Sato T, Kurisaki T, Kamijo K, Nabeshima Y and Fujisawa-Sehara A: A metalloprotease-disintegrin participating in myoblast fusion. Nature 377: 652-656, 1995.

47. Bernstein HG, Keilhoff G, Bukowska A, Ziegeler A, Funke S, Dobrowolny H, Kanakis D, Bogerts B and Lendeckel U: ADAM (a disintegrin and metalloprotease) 12 is expressed in rat and human brain and localized to oligodendrocytes. J Neurosci Res 75: 353-360, 2004.

48. Kanakis D, Lendeckel U, Theodosiou P, Dobrowolny H, Mawrin C, Keilhoff G, Bukowska A, Dietzmann K, Bogerts B and Bernstein HG: ADAM 12: A putative marker of oligodendrogliomas? Dis Markers 34: 81-91, 2013.

49. Huang PL, Dawson TM, Bredt DS, Snyder SH and Fishman MC: Targeted disruption of the neuronal nitric oxide synthase gene. Cell 75: 1273-1286, 1993.

50. Brenman JE, Xia H, Chao DS, Black SM and Bredt DS: Regulation of neuronal nitric oxide synthase through alternative transcripts. Dev Neurosci 19: 224-231, 1997.

51. Gödecke A, Decking UK, Ding Z, et al: Coronary hemodynamics in endothelial NO synthase knockout mice. Circ Res 82 186-194, 1998.

52. Corradin SB, Mauël J, Donini SD, Quattrocchi E and Ricciardi-Castagnoli P: Inducible nitric oxide synthase activity of cloned murine microglial cells. Glia 7: 255-262, 1993.

53. Richter-Landsberg C and Heinrich M: OLN-93: A new permanent oligodendroglia cell line derived from primary rat brain glial cultures. J Neurosci Res 45: 161-173, 1996.

54. Wex T, Treiber G, Lendeckel U and Malfertheiner P: A two-step method for the extraction of high-quality RNA from endoscopic biopsies. Clin Chem Lab Med 41: 1033-1037, 2003.

55. Härdtner C, Mörke C, Walther R, Wolke C and Lendeckel U: High glucose activates the alternative ACE2/Ang-(1-7)/Mas and APN/Ang IV/IRAP RAS axes in pancreatic $\beta$-cells. Int J Mol Med 32: 795-804, 2013

56. Schild L, Reinheckel T, Reiser M, Horn TF, Wolf G and Augustin W: Nitric oxide produced in rat liver mitochondria causes oxidative stress and impairment of respiration after transient hypoxia. FASEB J 17: 2194-2201, 2003

57. Gilpin BJ, Loechel F, Mattei MG, Engvall E, Albrechtsen R and Wewer UM: A novel, secreted form of human ADAM 12 (meltrin alpha) provokes myogenesis in vivo. J Biol Chem 273: 157-166, 1998.

58. Kveiborg M, Albrechtsen R, Couchman JR and Wewer UM: Cellular roles of ADAM12 in health and disease. Int J Biochem Cell Biol 40: 1685-1702, 2008.

59. Roy R, Wewer UM, Zurakowski D, Pories SE and Moses MA ADAM 12 cleaves extracellular matrix proteins and correlates with cancer status and stage. J Biol Chem 279: 51323-51330, 2004

60. Roy R, Zurakowski D, Pories S, Moss ML and Moses MA: Potential of fluorescent metalloproteinase substrates for cancer detection. Clin Biochem 44: 1434-1439, 2011.

61. Fröhlich C, Albrechtsen R, Dyrskjøt L, Rudkjaer L, Ørntoft TF and Wewer UM: Molecular profiling of ADAM12 in human bladder cancer. Clin Cancer Res 12: 7359-7368, 2006 
62. Roy R, Rodig S, Bielenberg D, Zurakowski D and Moses MA ADAM12 transmembrane and secreted isoforms promote breast tumor growth: A distinct role for ADAM12-S protein in tumor metastasis. J Biol Chem 286: 20758-20768, 2011.

63. Ohlig S, Farshi P, Pickhinke U, van den Boom J, Höing S, Jakuschev S, Hoffmann D, Dreier R, Schöler HR, Dierker T, et al: Sonic hedgehog shedding results in functional activation of the solubilized protein. Dev Cell 20: 764-774, 2011.

64. Pögün $\mathrm{S}$ and Kuhar MJ: Regulation of neurotransmitter reuptake by nitric oxide. Ann NY Acad Sci 738: 305-315, 1994.

65. Boehning D and Snyder SH: Novel neural modulators. Annu Rev Neurosci 26: 105-131, 2003.

66. Mukherjee P, Cinelli MA, Kang S and Silverman RB: Development of nitric oxide synthase inhibitors for neurodegeneration and neuropathic pain. Chem Soc Rev 43: 6814-6838, 2014.

67. Pepicelli O, Brescia A, Gherzi E, Raiteri M and Fedele E: GABA(A), but not NMDA, receptors modulate in vivo NO-mediated cGMP synthesis in the rat cerebral cortex. Neuropharmacology 46: 480-489, 2004.

68. Bernstein HG, Keilhoff G, Seidel B, Stanarius A, Huang PL, Fishman MC, Reiser M, Bogerts B and Wolf G: Expression of hypothalamic peptides in mice lacking neuronal nitric oxide synthase: Reduced beta-END immunoreactivity in the arcuate nucleus. Neuroendocrinology 68: 403-411, 1998.

69. Bredt DS and Snyder SH: Nitric oxide, a novel neuronal messenger. Neuron 8: 3-11, 1992.

70. Nathan C and Xie QW: Regulation of biosynthesis of nitric oxide. J Biol Chem 269: 13725-13728, 1994.

71. Gross SS and Wolin MS: Nitric oxide: Pathophysiological mechanisms. Annu Rev Physiol 57: 737-769, 1995.
72. Blaise GA, Gauvin D, Gangal M and Authier S: Nitric oxide, cell signaling and cell death. Toxicology 208: 177-192, 2005.

73. Pou S, Keaton L, Surichamorn W and Rosen GM: Mechanism of superoxide generation by neuronal nitric-oxide synthase. J Biol Chem 274: 9573-9580, 1999.

74. Yanik M, Vural H, Tutkun H, Zoroğlu SS, Savaş HA, Herken H, Koçyiğit A, Keleş $\mathrm{H}$ and Akyol O: The role of the arginine-nitric oxide pathway in the pathogenesis of bipolar affective disorder. Eur Arch Psychiatry Clin Neurosci 254: 43-47, 2004.

75. Jung $\mathrm{J}, \mathrm{Na} \mathrm{C}$ and Huh Y: Alterations in nitric oxide synthase in the aged CNS. Oxid Med Cell Longev 2012: 718976, 2012.

76. Gibbs SM: Regulation of neuronal proliferation and differentiation by nitric oxide. Mol Neurobiol 27: 107-120, 2003.

77. Dyczynska E, Sun D, Yi H, Sehara-Fujisawa A, Blobel CP and Zolkiewska A: Proteolytic processing of delta-like 1 by ADAM proteases. J Biol Chem 282: 436-444, 2007.

78. Chang AC, Fu Y, Garside VC, Niessen K, Chang L, Fuller M, Setiadi A, Smrz J, Kyle A, Minchinton A, et al: Notch initiates the endothelial-to-mesenchymal transition in the atrioventricular canal through autocrine activation of soluble guanylyl cyclase. Dev Cell 21: 288-300, 2011.

79. Pei H, Yu Q, Xue Q, Guo Y, Sun L, Hong Z, Han H, Gao E, Qu Y and Tao L: Notch1 cardioprotection in myocardial ischemia/reperfusion involves reduction of oxidative/nitrative stress. Basic Res Cardiol 108: 373, 2013.

80. Li H, Solomon E, Duhachek Muggy S, Sun D and Zolkiewska A: Metalloprotease-disintegrin ADAM12 expression is regulated by Notch signaling via microRNA-29. J Biol Chem 286: 21500-21510, 2011 